\title{
Comparative health-related fatty acid profiles, atherogenicity and desaturase indices of marula seed cake products from South Africa and Eswatini
}

Doctor M.N. Mthiyane ${ }^{1, *}$, Arno Hugo ${ }^{2}$

${ }^{1}$ Department of Animal Science, School of Agricultural Sciences, Faculty of Natural and Agricultural Sciences, North-West University, Mmabatho, 2735, South Africa; Doc.Mthiyane@nwu.ac.za

${ }^{2}$ Department of Microbial, Biochemical and Food Biotechnology, Faculty of Natural and Agricultural Sciences, University of the Free State, Bloemfontein, 9300, South Africa; HugoA@ufs.ac.za

*Correspondence: kakade2000@ gmail.com; Tel.: +27 673328933 (mobile)

\begin{abstract}
Marula seed cake (MSC) is a nutritionally-rich natural feed resource that can enhance the healthiness of animal-derived foods (ADFs) for human consumption. This study compared the health-related fatty acid (FA) profiles of MSC products from South Africa and Eswatini. Composite samples monthly collected from both countries were analysed for FAs. MSC products from both countries were found to be dominated by oleic acid (>70\%), followed by palmitic, linoleic and stearic acids. Consequently, both products had their FA totals dominated by $\Sigma$ MUFA followed by $\Sigma$ SFA, $\Sigma$ PUFA, $\Sigma n-6$ PUFA and $\Sigma n-3$ PUFA. Both oleic and stearic
\end{abstract}


acids were higher $(\mathrm{P}<0.01)$ whilst linoleic $(\mathrm{P}<0.001), \alpha$-linolenic $(\mathrm{P}<0.05)$, margaric $(\mathrm{P}<$ 0.05), palmitoleic $(\mathrm{P}<0.05)$ and eicosatrienoic $(\mathrm{P}<0.05)$ acids were lower in South African in comparison to Eswatini MSC. Consequently, South African MSC had higher $\Sigma$ MUFA $(\mathrm{P}<$ $0.01)$ but lower $\Sigma$ PUFA $(\mathrm{P}<0.001), \Sigma n-6$ PUFA $(\mathrm{P}<0.001)$ and $\Sigma n-3$ PUFA $(\mathrm{P}<0.05)$. Also, Eswatini MSC had higher $n-6: n-3$ PUFA, PUFA : SFA $(\mathrm{P}=0.001)$ and PUFA : MUFA $(\mathrm{P}<$ $0.05)$ ratios. Further, MSC products from both countries had similarly $(\mathrm{P}>0.05)$ low atherogenicity and high desaturase indices. In conclusion, both country products are rich particularly in oleic acid and their incorporation into farm animal diets would increase content of the MUFA in ADFs and, consequently, improve health benefits to human consumers.

Keywords: marula, seed (kernel) cake, fatty acids, fatty acid totals, fatty acid ratios, atherogenicity and desaturase indices

\section{Introduction}

One major challenge facing the world particularly in Africa is massive human population growth at a rate that surpasses the capacity to produce sufficient food to nourish the growing masses. The global human population is forecast to surpass 9 billion by 2050 , necessitating > $50 \%$ increase in food productivity [1]. Apart from plants (crops), animal-derived foods (ADFs) represent the major source of nutrition to the ever growing human populations and constitute a significant portion of current national diets in Africa and globally [2, 3]. For example, from 2003 to 2015 the South African per capita consumption of total meats (including beef, pork, veal, lamb, poultry, fish, and shellfish) and milk increased by $54.4 \%$ to $66.83 \mathrm{~kg} / \mathrm{year}$ [4]. 
However, the healthiness and nutritional quality of ADFs is compromised by the feedstuffs that are fed to animals on farms. In an attempt to enhance animal productivity, reduce feed costs and increase profits, industrialized livestock and poultry producers incorporate in their animal diets a myriad of unnatural and sometimes ethically questionable feedstuffs that raise concerns for public health. These include rendered animal products, animal wastes such as chicken (broiler) litter and manure, rumen contents, hormones, antibiotics, organo-arsenicals and others [5-7]. Incorporation of these ingredients into animal feeds can result in the presence of a range of biological, chemical, and other etiologic agents in feed that can affect the quality and safety of $\mathrm{ADF}$ and pose potential risks to human health $[8,9]$. Indeed, a growing body of evidence shows that the use of such unnatural feed resources as animal feed is detrimental to the health and wellbeing of human consumers $[6,10,11]$ and may underlie the rapid proliferation of the so-called lifestyle diseases of Western civilization such as cardiovascular disease (CVD), diabetes, cancer, stroke and others $[12,13]$. This may explain the significant decline in the demand for certain traditional types of meat such as beef and mutton over the last few decades, as perceived health concerns surrounding red meat consumption increase [14, 15].

In contrast, use of natural plant-based feedstuffs and oils results in production of ADFs that are healthy for human consumption. Many studies have demonstrated that use of such natural feed resources enhances the healthiness of ADFs by altering their fatty acid (FA) composition away from the saturated (SFA) towards the unsaturated -MUFA and PUFA - profile and lower $n-6$ : $n$-3 PUFA ratios [16 - 19]. Also, supplementation of beef cattle diets with the leaf meal of Melia azedarach in replacement of broiler litter, inter alia, increased beef kidney fat $\alpha$-linoleic acid (n-3), conjugated linoleic acid (CLA) and $\Sigma n-3$ PUFA whilst it decreased the $n-6: n-3$ PUFA ratio [20]. Meat with high levels of $n-3$ PUFAs and CLA, as well as a low $n-6: n-3$ PUFA ratio (optimal values $\leq 4$ ), is said to decrease the risk of cardiovascular disease and other 
chronic disorders [21]. There is therefore a need for a paradigm shift in the way farm animals are fed towards use of natural feedstuffs that are not only healthy to them but to human consumers as well [22].

The MSC is a by-product of oil extraction from the kernels (nuts) of the ripe fruit seeds of marula (Sclerocarya birrea A. Rich.), an indigenous fruit tree distributed throughout most of sub-Saharan Africa from $17^{\circ} 15^{\prime} \mathrm{N}$ in the Aïr Mountains of Niger to $31^{\circ} 00^{\prime} \mathrm{S}$ near Port Shepstone in South Africa [23, 24]. It is commercially produced by several small-scale firms in South Africa and Eswatini $[25,20]$ and is used by local people as animal feed and human food, particularly snacks. It is a novel locally available alternative protein supplement (CP: 470 $\mathrm{g} / \mathrm{kg} \mathrm{DM}$ ) for beef and dairy cattle [26, 27], goats [28], sheep [25] and poultry [20, 29]. Of particular interest, MSC is naturally endowed with a highly desirable FA composition that can enormously enhance the oxidative stability and healthiness of ADFs for human consumption. In this regard, its abundant residual oil (EE: 343.5 - $411.32 \mathrm{~g} / \mathrm{kg} \mathrm{DM}$ ) has an extremely high content of oleic acid $(74 \%-85 \%)$ [20, 30], a hypo-cholesterolemic [31, 32], antiatherosclerotic and anti-diabetic [33 - 36] MUFA with an extremely high oxidative stability that is 10x more than that of olive oil [37 - 39]. The oil's remarkable oxidative stability has long been exploited in Africa, especially for meat preservation [40]. Also, the oil in MSC contains some essential FAs (EFAs) linoleic and $\alpha$-linolenic acids whose dietary incorporation into ADFs would help in the fight against human illnesses like rheumatoid arthritis [41] and diabetics [42]. Therefore, incorporation of MSC into animal diets in Southern African where this product is produced would not only supply much needed protein, energy and other nutrients, but would also enhance the shelf-life and health status of meat and other ADFs that would, consequently, improve health benefits to human consumers. However, in light of the high phenotypic variation in nut and kernel traits [43] as well as intra-population genetic diversity 
among S. birrea populations [44], we hypothesized that there would also be significant differences in the FA composition and healthiness of MSC from different regions in Southern Africa. The objective of this study was therefore to compare the FA composition of MSC products produced in South Africa and Eswatini.

\section{Materials and methods}

Samples $(1 \mathrm{~kg})$ of MSC were monthly collected between March and June 2018 from Marula Oil Production (MOP) Cooperative in Bushbuckridge (Limpopo province, South Africa) and from Swazi Secrets in the Lubombo region of Eswatini (formerly Swaziland). The samples were kept in polyethylene bags pending analysis. After the last sampling in June, a composite sample was prepared for each country and submitted for FA analysis at the Lipid Chemistry Laboratory of the Department of Microbial, Biochemical and Food Biotechnology at the University of the Free State.

Total lipid from MSC was quantitatively extracted according to the method of Folch et al. [45], using chloroform and methanol in a ratio of $2: 1$. An antioxidant, butylated hydroxytoluene was added at a concentration of $0.001 \%$ to the chloroform: methanol mixture. A rotary evaporator was used to dry the fat extracts under vacuum and the extracts were dried overnight in a vacuum oven at $50{ }^{\circ} \mathrm{C}$, using phosphorus pentoxide as a moisture adsorbent. Total extractable MSC fat was determined gravimetrically from the extracted fat and expressed as $\%$ fat $(\mathrm{w} / \mathrm{w})$ per $100 \mathrm{~g}$ sample. The extracted fat was stored in a polytop (glass vial, with push-in top) under a blanket of nitrogen and frozen at $-20{ }^{\circ} \mathrm{C}$ pending FA analyses.

A lipid aliquot $( \pm 30 \mathrm{mg})$ of sausage batter lipid were converted to methyl esters by basecatalysed trans-esterification in order to avoid CLA isomerisation, with sodium methoxide $(0.5$ 
M solution in anhydrous methanol) during $2 \mathrm{~h}$ at $30{ }^{\circ} \mathrm{C}$, as proposed by Park et al. [46], Kramer et al. [47] and Alfaia et al. [48]. Fatty acid methyl esters (FAMEs) from sausage batter lipid were quantified using a Varian 430 flame ionization GC, with a fused silica capillary column, Chrompack CPSIL 88 (100 m length, $0.25 \mathrm{~mm}$ ID, $0.2 \mu \mathrm{m}$ film thicknesses). Analysis was performed using an initial isothermic period $\left(40{ }^{\circ} \mathrm{C}\right.$ for 2 minutes). Thereafter, temperature was increased at a rate of $4{ }^{\circ} \mathrm{C} /$ minute to $230{ }^{\circ} \mathrm{C}$. Finally an isothermic period of $230{ }^{\circ} \mathrm{C}$ for 10 minutes followed. FAMEs n-hexane $(1 \mu \mathrm{l})$ was injected into the column using a Varian CP 8400 Autosampler. The injection port and detector were both maintained at $250{ }^{\circ} \mathrm{C}$. Hydrogen, at 45 psi, functioned as the carrier gas, while nitrogen was employed as the makeup gas. Galaxy Chromatography Data System Software recorded the chromatograms.

FAME samples were identified by comparing the retention times of FAME peaks from samples with those of standards obtained from Supelco (Supelco 37 Component Fame Mix 47885-U, Sigma-Aldrich Aston Manor, Pretoria, South Africa). CLA standards were obtained from Matreya Inc. (Pleasant Gap, Unites States). These standards included: cis-9, trans-11 and trans10, cis-12-18:2 isomers.

FAs were expressed as the proportion of each individual FA to the total of all FAs present in the sample. FA data were used to calculate the following ratios of FAs: $\Sigma$ SFAs, $\Sigma$ MUFAs, $\Sigma$ PUFAs, PUFA/SFA, $\Delta^{9}$-desaturase index (DI) (C18:1c9 / C18:0), $\Sigma n-6$ PUFA, $\Sigma n-3$ PUFA, and the $n-6: n-3$ PUFA ratio. Atherogenicity index (AI) was calculated as: $\mathrm{AI}=(\mathrm{C} 12: 0+4 \mathrm{x}$ C14:0 + C16:0) / (MUFA + PUFA) [49].

\subsection{Statistics}


Results are reported as means \pm standard deviation $(\mathrm{n}=2)$. Non-detected FAs were considered as 0 value for statistical analysis. Normal distribution was checked for all data with the onesample Kolmogorov-Smirnoff test and homogeneity of variances with the Levene test. Differences between pairs of means were tested using Student's t-test. In all tests used, statistical significance was accepted at $\mathrm{P}<0.05$ level of probability. All statistical analysis were carried out using the Minitab [50] package.

\section{Results and Discussion}

Our data showed oleic acid to be the predominant FA species in oil from MSC from both South Affrica (74.4\%) and Eswatini (72.0\%) (Table 1). Consequently, the FA totals of oil from MSC from both countries were respectively dominated by the $\Sigma$ MUFA (74.5\% and $72.2 \%$ ) (Table 2). Oleic acid was, respectively, followed by palmitic ( $11.3 \%$ vs. $11.7 \%)$, LA (6.7\% vs. $8.7 \%$ ) and stearic (6.3\% vs. $6.0 \%)$ acids. Evidently due to appreciable amounts of palmitic and stearic acids, the oil in MSC products from both countries had cumulatively large amounts of $\Sigma$ SFA (South Africa: 18.4\% and Eswatini: 18.6\%). These findings corroborate previous studies in South Africa [30, 51 - 53], Eswatini [20], Botswana [54], Namibia [55], Niger [38], Ethiopia [56], Sudan [57] and Zimbabwe [58], which found a preponderance of oleic acid (60 - 88\%) followed by palmitic and stearic acids in marula kernel oil.

Also, the oil from both South Africa and Eswatini MSC products was found to contain smaller amounts $(<1 \%)$ of, respectively, arachidic $(0.47 \%$ vs. $0.47 \%), \alpha$-linolenic acid $(0.3 \%$ vs. $0.34 \%)$, margaric $(0.13 \%$ vs. $0.18 \%)$, lignoceric ( $0.13 \%$ vs. $0.15 \%)$, palmitoleic $(0.11 \%$ vs. $0.14 \%$ ), eicosatrienoic ( $0.10 \%$ vs. $0.12 \%)$, and other acids (Table 1$)$. As a consequence of low amounts of linoleic acid, $\alpha$-linolenic acid and other PUFA, both the South African and Eswatini MSC products had oil with rather low amounts of $\Sigma$ PUFA ( $7.1 \%$ and $9.2 \%$, respectively), $\Sigma n$ - 
6 PUFA (6.8\% and $8.9 \%$, respectively) and $\Sigma n-3$ PUFA $(0.3 \%$ and $0.3 \%$, respectively) (Table 2). Other studies found similarly low amounts of arachidic, $\alpha$-linolenic acid, margaric, lignoceric, palmitoleic, eicosatrienoic, and other acids in marula seed kernel oil [59, 30].

Table 1. Fatty acid composition (FAME \% of total FAs) of oil from marula seed cake from South Africa and Eswatini

\begin{tabular}{|c|c|c|c|c|}
\hline Fatty acid (\%) & Trivial name & South Africa & Eswatini & $P$-value \\
\hline \multicolumn{5}{|c|}{ Saturated fatty acids } \\
\hline $\mathrm{C} 4: 0$ & Butyric & - & - & - \\
\hline C6:0 & Caproic & - & - & - \\
\hline C8:0 & Caprylic & - & - & - \\
\hline C10:0 & Capric & $0.02 \pm 0.01$ & - & - \\
\hline C12:0 & Lauric & - & - & - \\
\hline C14:0 & Myristic & $0.04 \pm 0.01$ & $0.04 \pm 0.01$ & $\mathrm{P}>0.05$ \\
\hline C18:0 & Stearic & $6.26 \pm 0.01$ & $6.01 \pm 0.01$ & $\mathrm{P}<0.01$ \\
\hline C16:0 & Palmitic & $11.30 \pm 0.11$ & $11.70 \pm 0.11$ & $\mathrm{P}>0.05$ \\
\hline $\mathrm{C} 17: 0$ & Margaric & $0.13 \pm 0.005$ & $0.18 \pm 0.005$ & $\mathrm{P}<0.05$ \\
\hline C20:0 & Arachidic & $0.47 \pm 0.01$ & $0.47 \pm 0.01$ & $\mathrm{P}>0.05$ \\
\hline $\mathrm{C} 21: 0$ & Heneicosanoic & - & $0.02 \pm 0.00$ & - \\
\hline C19:0 & Nonadecanoic & $0.04 \pm 0.01$ & $0.06 \pm 0.01$ & $\mathrm{P}>0.05$ \\
\hline $\mathrm{C} 15: 0$ & Pentadecyclic & - & - & - \\
\hline $\mathrm{C} 24: 0$ & Lignoceric & $0.13 \pm 0.01$ & $0.15 \pm 0.01$ & $P>0.05$ \\
\hline
\end{tabular}

\section{Unsaturated fatty acids}




\begin{tabular}{|c|c|c|c|c|}
\hline $\mathrm{C} 14: 1 c 9$ & Myristoleic & - & - & - \\
\hline $\mathrm{C} 16: 1 c 9$ & Palmitoleic & $0.11 \pm 0.01$ & $0.14 \pm 0.01$ & $\mathrm{P}<0.05$ \\
\hline C18:1t9 & Elaidic & - & - & - \\
\hline C18:1c9 & Oleic & $74.41 \pm 0.13$ & $72.02 \pm 0.13$ & $\mathrm{P}<0.01$ \\
\hline C18:1t11 & Vaccenic & - & - & - \\
\hline $\mathrm{C} 18: 2 t 9,12 \quad(n-$ & Linolelaidic & - & - & - \\
\hline \multicolumn{5}{|l|}{ 6) } \\
\hline $\mathrm{C} 18: 2 c 9,12 \quad(n-$ & Linoleic & $6.68 \pm 0.04$ & $8.74 \pm 0.04$ & $\mathrm{P}=0.001$ \\
\hline \multicolumn{5}{|l|}{ 6) } \\
\hline $\mathrm{C} 18: 3 c 9,12,15$ & $\alpha$-Linolenic & $0.30 \pm 0.004$ & $0.34 \pm 0.004$ & $\mathrm{P}<0.05$ \\
\hline \multicolumn{5}{|l|}{$(n-3)$} \\
\hline $\mathrm{C} 18: 2 c 9, t 11 \quad(n-$ & CLA & - & - & - \\
\hline \multicolumn{5}{|l|}{ 6) (CLA) } \\
\hline $\mathrm{C} 20: 2 c 11,14(n-$ & Eicosadienoic & $0.03 \pm 0.002$ & $0.03 \pm 0.002$ & $P>0.05$ \\
\hline \multicolumn{5}{|l|}{ 6) } \\
\hline $\mathrm{C} 20: 3 c 8,11,14$ & Eicosatrienoic & $0.10 \pm 0.002$ & $0.12 \pm 0.002$ & $\mathrm{P}<0.05$ \\
\hline \multicolumn{5}{|l|}{$(n-6)$} \\
\hline $\mathrm{C} 22: 1 c 13$ & Erucic & - & - & - \\
\hline $\mathrm{C} 20: 4 c 5,8,11,1$ & Arachidonic & - & - & - \\
\hline \multicolumn{5}{|l|}{$4(n-6)$} \\
\hline $\mathrm{C} 23: 0$ & Tricosanoic & - & - & - \\
\hline $\mathrm{C} 22: 5 c 7,10,13$, & DPA & - & - & - \\
\hline $16,19(n-3)$ & & & & \\
\hline
\end{tabular}

CLA, conjugated linoleic acid; DPA, docosapentaenoic acid. 
Table 2. Totals, ratios and indices of fatty acids in oil from marula seed cake from South Africa and Eswatini

\begin{tabular}{|c|c|c|c|}
\hline Item & South Africa & Eswatini & $P$-value \\
\hline$\Sigma$ SFA & $18.37 \pm 0.10$ & $18.61 \pm 0.10$ & $P>0.05$ \\
\hline$\Sigma$ MUFA & $74.52 \pm 0.13$ & $72.17 \pm 0.13$ & $\mathrm{P}<0.01$ \\
\hline$\Sigma$ PUFA & $7.11 \pm 0.04$ & $9.22 \pm 0.04$ & $\mathrm{P}=0.001$ \\
\hline$\Sigma n-6$ PUFA & $6.81 \pm 0.04$ & $8.89 \pm 0.04$ & $\mathrm{P}=0.001$ \\
\hline$\Sigma n-3$ PUFA & $0.30 \pm 0.004$ & $0.34 \pm 0.004$ & $\mathrm{P}<0.05$ \\
\hline PUFA : SFA & $0.39 \pm 0.002$ & $0.50 \pm 0.002$ & $\mathrm{P}=0.001$ \\
\hline PUFA : MUFA & $0.10 \pm 0.004$ & $0.13 \pm 0.004$ & $P<0.05$ \\
\hline$n-6: n-3$ PUFA & $22.82 \pm 0.09$ & $26.55 \pm 0.09$ & $\mathrm{P}=0.001$ \\
\hline Atherogenicity index & $0.14 \pm 0.004$ & $0.15 \pm 0.004$ & $P>0.05$ \\
\hline Desaturase index & $11.89 \pm 0.03$ & $11.98 \pm 0.03$ & $P>0.05$ \\
\hline
\end{tabular}

Interestingly, the oil in South African MSC had higher oleic $(\mathrm{P}<0.01)$ and stearic $(\mathrm{P}<0.01)$ but lower linoleic $(\mathrm{P}=0.001), \alpha$-linolenic acid $(\mathrm{P}<0.05)$, margaric $(\mathrm{P}<0.05)$, palmitoleic $(\mathrm{P}$ $<0.05)$ and eicosatrienoic $(\mathrm{P}<0.05)$ acid contents relative to the Eswatini product (Table 1$)$. Consequently, the South African MSC oil had higher $\Sigma$ MUFA $(\mathrm{P}<0.01)$ but lower $\Sigma$ PUFA (P $<0.001), \Sigma n-6$ PUFA $(\mathrm{P}<0.001)$ and $\Sigma n-3$ PUFA $(\mathrm{P}<0.05)$ (Table 2). Otherwise, all other SFAs, UFAs and $\Sigma$ SFAs were similar $(\mathrm{P}>0.05)$ in the oil from MSC products obtained from both countries (Tables 1 and 2). Notwithstanding the variation, the values of FAs and FA totals in the oil from South Africa and Eswatini MSC products are within the range of values obtained in previous studies $[20,30,58]$. The variation in the MSC oil FA composition and FA totals 
between the two countries might be due to marula tree genetic differences or variations in soil type, soil fertility status, rainfall patterns and harvesting time. Indeed, the FA composition and oil content of marula kernels can be affected by harvesting time, with an increase (up to $63 \%$ of dry weight) in the oil content obtained at the end (June) in comparison to the start (March) of the harvesting period [39]. Also, marula trees exhibit wide genetic variations [60], with their growth rate and fruit production also marginally linked to rainfall amount [61].

Our data also showed the oil from both South Africa and Eswatini MSC products to have remarkably high n-6:n-3 PUFA ratios (Table 2). Interestingly, this ratio was higher in the oil from Eswatini MSC than in that from the South African product $(P=0.001)$. Notwithstanding, both the South African and Eswatini MSC products had oil with exceedingly high $n-6: n-3$ PUFA ratios in comparison to those of modern (10:1 - 15:1) and primitive man (1:1) diets [62, 63]. This arises from the high content of linoleic acid in comparison to the $\Sigma n-3$ PUFAs in the oil from both country MSC samples. A high $n-6: n$-3 PUFA ratio is said to promote many noncommunicable diseases such as CVD, atherogenesis, arthritis, cancer, osteoporosis and inflammatory and autoimmune diseases whereas lower ratios have suppressive effects [6365]. However, despite the fact that the Eswatini MSC had a higher $n-6: n-3$ PUFA ratio in comparison to the South African product, it is unlikely that consumption of either product would cause any ill health to humans or animals as both marula by-products are extremely rich in oleic acid, a n-9 MUFA with hypo-cholesterolemic [31, 66, 67], anti-diabetic [68], antistroke [69], anti-cancer [70, 71], anti-obesity and anti-hypertension [72, 73] properties. If anything, the Eswatini MSC would appear to be even more healthier as its oil had higher PUFA : SFA $(P=0.001)$ and PUFA : MUFA $(P<0.05)$ ratios, as well as higher $\sum n-3$ PUFA $(P<0.05)$, in comparison to the South African product (Table 2). Increased intake of PUFAs relative to 
SFAs and $n$-3 PUFAs relative to $n-6$ PUFAs is highly recommended in the modern era of chronic diseases $[62,63,74]$.

Further, both the South African and Eswatini MSC products had similarly $(\mathrm{P}>0.05)$ low AI and high DI (Table 2). This is the first time that these indices have been determined in MSC. Nonetheless, the observed AI values are lower than those previously found in mucuna bean (0.26; Mthiyane et al., unpublished) and meat fats $(0.5-1.0)[75,76]$. High AI values indicate greater atherogenicity risk [77]. With low AI values, both the South African and Eswatini MSC products used in this study would therefore appear to be healthy for both human and animal consumption. On the other hand, the DI values of MSC products used in this study are noticeably higher than that (1.25) found in mucuna bean. Whilst the literature reports that a high DI is associated with obesity [78 - 80], hypertriacylglycerolaemia [81] and the metabolic syndrome [82], as well as with an increased risk to develop insulin resistance [83], cardiovascular death and total death [84], there are currently no recommended or normal values that should be expected in food/feed products.

\section{Conclusion}

Our data showed the FA composition of oil in both MSC products from South Africa and Eswatini to be dominated by oleic acid, followed by palmitic, linoleic and stearic acids, with smaller amounts of arachidic, $\alpha$-linolenic acid, margaric, lignoceric, palmitoleic, eicosatrienoic, and other acids. Consequently, both products had their FA totals dominated by the $\Sigma$ MUFA followed by the $\Sigma$ SFA and low amounts of $\Sigma$ PUFA, $\Sigma n-6$ PUFA and $\Sigma n-3$ PUFA. Both oleic and stearic acids were higher whilst linoleic, $\alpha$-linolenic, margaric, palmitoleic and eicosatrienoic acids were lower in oil from South African MSC in comparison to the Eswatini product. Consequently, the South African product's oil had higher $\Sigma$ MUFA but lower $\Sigma$ PUFA, 
$\Sigma n-6$ PUFA and $\Sigma n-3$ PUFA. Also, whilst the oil from both the South African and Eswatini MSC products had remarkably high $n-6: n-3$ PUFA ratios, the latter product's oil was superior in this regard, as it was with respect to PUFA : SFA and PUFA : MUFA ratios. Further, both MSC products had similarly low AI and high DI. With the observed extremely high oleic acid content, incorporation of either product into livestock and poultry diets would be expected to increase the level of the MUFA in the meat, milk and eggs and, consequently, improve health benefits to human consumers.

Author Contributions: DMNM conceptualized and executed the study, analyzed the data and wrote the manuscript whilst $\mathrm{AH}$ analyzed the samples, reviewed and edited the manuscript. All authors have read and approved the final manuscript.

Funding: This research received no external funding.

\section{Acknowledgements}

We are grateful to Swazi Secrets (Pty) Ltd (Eswatini), Mr. Reggie Themeli and Prof. Ignatius Verla Nsahlai for the supply of MSC samples. We are equally indebted to Ms. Eileen Roodt for the laboratory analysis of fatty acids.

Conflict of Interest: The authors declare no conflicts of interest. 


\section{References}

1. Ingram, J.; Ericksen P.; Liverman, D. Food Security and Global Environmental Change. Earthscan, London, 2010.

2. Henchion, M; Hayes, M; Mullen, A.M.; Fenelon, M; Tiwari, B. Future protein supply and demand: strategies and factors influencing a sustainable equilibrium. Foods 2017, $6,1-21$

3. Enahoro, D; Lannerstad, M; Pfeifer, C; Dominguez-Salas, P. Contributions of livestock-derived foods to nutrient supply under changing demand in low- and middleincome countries. Glob. Food Secur. 2018, 19, 1 - 10.

4. Abstract of Agricultural Statistics. Department of Agriculture, Forestry and Fisheries (DAFF); Pretoria, South Africa, 2016.

5. Lefferts, L.Y.; Kucharski, M.; McKenzie, S.; Walker, P. Feed for food-producing animals: a resource on ingredients, the industry, and regulation. The Johns Hopkins Center for a Livable Future. Bloomberg School of Public Health, Baltimore, USA, 2007. Available online: https://www.jhsph.edu/research/centers-and-institutes/johnshopkins-center-for-a-livable-future/_pdf/research/clf_reports/animal_feed.pdf (Accessed 10 August 2019).

6. Sapkota, A.R.; Lefferts, L.Y.; McKenzie, S.; Walker, P. What do we feed to foodproduction animals? a review of animal feed ingredients and their potential impacts on human health. Environ. Health Perspect. 2007, 115, 663 - 670.

7. Alao, B.O.; Falowo, A.B.; Chulayo, A.; Muchenje, V. The potential of animal byproducts in food systems: production, prospects and challenges. Sustainab. 2017, 9, 1089. 
8. Dórea, J.G. Fish meal in animal feed and human exposure to persistent bioaccumulative and toxic substances. J. Food Prot. 2006, 69, 2777 - 2785.

9. Sharma, V.; Sharma, S. Feeding safe feed to livestock safeguards human health. Feedipedia, Broadening Horiz. 2017, 37, 1 - 6. Available online: https://www.feedipedia.org/content/feeding-safe-feed-livestock-safeguards-humanhealth (Accessed 12 August 2019).

10. World Health Organization (WHO). Dioxins and their effects on human health. Fact Sheet No 225, 2014. Available online: http://www.who.int/mediacentre/factsheets/fs225/en/ (Accessed on 17 October 2019).

11. Jędrejek, D.; Levic, J.; Wallace, J.; Oleszek, W. Animal by-products for feed: characteristics, European regulatory framework, and potential impacts on human and animal health and the environment. J. Anim. Feed Sci. 2016, 25, 189 - 202.

12. Schulze, M.B.; Martínez-González, M.A.; Fung, T.T.; Lichtenstein, A.H.; Forouhi, N.G. Food based dietary patterns and chronic disease prevention. Brit. Med. J. 2018, $361, \mathrm{k} 2396$.

13. Afshin, A.; Sur, P.J.; Fay, K.A.; Cornaby, L.; Ferrara, G.; Salama, J.S.; Mullany, E.C.; et al. Health effects of dietary risks in 195 countries, 1990 - 2017: a systematic analysis for the Global Burden of Disease Study 2017. Lancet 2019, 393, 1958 - 1972.

14. Kearney, J. Food consumption trends and drivers. Philos. Trans. R. Soc., B. 2010, 365, $2793-2807$.

15. Kanerva, M. Meat consumption in Europe: issues, trends and debates. Artec, Bremen, 2013. Available online: file:///C:/Users/28199642/Downloads/187_paper.pdf (Accessed 10 August 2019). 
16. Mavimbela, D.T.; Webb, E.C.; Van Ryssen, J.B.J.; Bosman, M.J.C. Sensory characteristics of meat and composition of carcass fat from sheep fed diets containing various levels of broiler litter. S. Afr. J. Anim. Sci. 2000, 30, 26 - 32.

17. Mpofu, D.A.; Marume, U.; Mlambo, V.; Hugo, A. The effects of Lippia javanica dietary inclusion on growth performance, carcass characteristics and fatty acid profiles of broiler chickens. Anim. Nutr. 2016, 2, $160-167$.

18. Hossain, M.E.; Kim, G.M.; Sun, S.S.; Firman, J.D.; Yang, C.J. Evaluation of water plantain (Alisma canaliculatum A. Br. et Bouche) and mistletoe (Viscum album L.) effects on broiler growth performance, meat composition and serum biochemical parameters. J. Med. Plants Res. 2012, 6, 2160 - 2169.

19. Nyquist, N.F.; Rødbotten, R.; Thomassen, M.; Haug, A. Chicken meat nutritional value when feeding red palm oil, palm oil or rendered animal fat in combinations with linseed oil, rapeseed oil and two levels of selenium. Lipids Health Dis. 2013, 12, 69.

20. Mthiyane, D.M.N.; Mhlanga, B.S. The nutritive value of marula (Sclerocarya birrea) seed cake for broiler chickens: nutritional composition, performance, carcass characteristics and oxidative and mycotoxin status. Trop. Anim. Health Prod. 2017, 49, $835-842$.

21. Simopoulos, A.P. The importance of the omega-6/omega-3 fatty acid ratio in cardiovascular disease and other chronic diseases. Exp. Biol. Med. 2008, 233, $674-$ 688.

22. Pulina, G.; Francesconi, A.H.D.; Stefanon, B.; Sevi, A.; Calamari, L.; Lacetera, N.; Dell'Orto, V.; Pilla, F.; Marsan, P.A.; Mele, M.; Rossi, F.; Bertoni, G.; Crovetto, G.M.; Ronchi, B. Sustainable ruminant production to help feed the planet. Italian J. Anim. Sci. 2017, $16,140-171$. 
23. Hall, J.B.; O’brien, E.M.; Sinclair, F.L. Sclerocarya birrea: A Monograph; School of Agricultural and Forest Sciences Publication No. 19: University of Wales, Bangor, UK, 2002, p. 157.

24. Chirwa, P.W.; Akinnifesi, F.K. Ecology and biology of Uapaca kirkina, Strychnos cocculoides and Sclerocarya birrea in Southern Africa. In: Indigenous Fruit Trees in the Tropics: Domestication, Utilisation and Commercialisation; Akinnifesi, F.K., Leakey, R.R.B., Ajayi, O.C., Sileshi, G., Tchoundjeu, Z., Matakala, P., Kwesiga, F.R., Eds.; CABI International: London, UK, 2008; pp. 322 - 340.

25. Malebana, I. M. M. Dietary effects of Sclerocarya birrea caffra nut meal in growingfattening male dorper sheep. $\mathrm{PhD}$ Thesis, University of the Witwatersrand, South Africa, 2018.

26. Mlambo, V.; Dlamini, B.J.; Ngwenya, M.D.; Mhazo, N.; Beyene, S.T.; Sikosana J.L.N. In sacco and in vivo evaluation of marula (Sclerocarya birrea) seed cake as a protein source in commercial cattle fattening diets. Liv. Res. Rur. Dev. 2011a, 23.

27. Mdziniso, P.M.; Dlamini, A.M.; Khumalo, G.Z.; Mupangwa, J.F. Nutritional evaluation of marula (Sclerocarya birrea) seed cake as a protein supplement in dairy meal. J. Appl. Life Sci. Intl 2016, 4, 1 - 11.

28. Mlambo, V.; Dlamini, B.J.; Nkambule, M.T.; Mhazo, N.; Sikosana J.L.N. Nutritional evaluation of marula (Sclerocarya birrea) seed cake as a protein supplement for goats fed grass hay. Trop. Agric. (Trinidad) 2011b, 88, $35-43$.

29. Mazizi, B.E.; Moyo, D.; Erlwanger, K.W.; Chivandi, E. Effects of dietary Sclerocarya birrea caffra (marula) nut meal on the growth performance and viscera macromorphometry of broiler Japanese quail. Appl. Poult. Res. 2019, 0, 1 - 11.

30. Malebana, I.M.M.; Nkosi, B.D.; Erlwanger, K.H.; Chivandi, E. A comparison of the proximate, fibre, mineral content, amino acid and the fatty acid profile of marula 
(Sclerocarya birrea caffra) nut and soyabean (Glycine max) meals. J. Sci. Food Agric. 2017, 98, $1381-1387$.

31. Kurushima, H.; Hayashi, K.; Toyota, Y.; Kambe, M.; Kajiyama, G. Comparison of hypocholesterolemic effects induced by dietary linoleic acid and oleic acid in hamsters. Atheroscl. 1995, 114, $213-221$.

32. Griffin, M.E.; Dimitriadis, E.; Lenehan, K.; Owens, D.; Collins, P.; Johnson, A.; Tomkin, G.H. Non-insulin-dependent diabetes mellitus: dietary monounsaturated fatty acids and low-density lipoprotein composition and function. QJM: Intl J. Med. 1996, $89,211-216$.

33. Ryan, M.; McInerney, D.; Owens, D.; Collins, P.; Johnson, A.; Tomkin, G.H. Diabetes and the Mediterranean diet: a beneficial effect of oleic acid on insulin sensitivity, adipocyte glucose transport and endothelium-dependent vasoreactivity. QJM: Intl J. Med. 2000, 93, $85-91$.

34. Soriguer, F.; Esteva, I.; Rojo-Martínez, G.; Ruiz de Adana, M.S.; Dobarganes, M.C.; García-Almeida, J.M.; Tinahones, F.; Beltrán, M.; González-Romero, S.; Olveira, G.; Gómez-Zumaquero, J.M. Oleic acid from cooking oils is associated with lower insulin resistance in the general population (Pizarra study). Eur. J. Endocrinol. 2004, 150, 33 -39 .

35. Vassiliou, E.K.; Gonzalez, A.; Garcia, C.; Tadros, J.H.; Chakraborty, G.; Toney, J.H. Oleic acid and peanut oil high in oleic acid reverse the inhibitory effect of insulin production of the inflammatory cytokine TNF- $\alpha$ both in vitro and in vivo systems. Lipids Health Dis. 2009, 8, 25 - 34.

36. Kuna, A.; Achinna, P. Monounsaturated fatty acids for CVD and diabetes: a healthy choice. Intl J. Nutr. Pharmacol. Neurolog. Dis. 2013, 3, 236 - 248. 
37. Burger, A.E.C.; De Villiers, J.B.M.; Du Plessis, L.M. Composition of the kernel oil and protein of the marula seed. S. Afr. J. Sci. 1987, 83, $733-735$.

38. Glew, R.S.; Vanderjagt, D.J.; Huang, Y.-S.; Glew, R.H. Nutritional analysis of the edible pit of Sclerocarya birrea in the Republic of Niger (daniya, Hausa). J. Food Composit. Anal. 2004, 17, 1, 99 - 111.

39. Mariod, A.A.; Abdelwahab, S.I. Sclerocarya birrea (marula), an African tree of nutritional and medicinal uses: a review. Food Rev. Intl. 2012, 28, 375 - 388.

40. Palmer, E.; Pitman, N. Trees of Southern Africa. A. A. Balkema, Cape Town, 1972.

41. Lands, W.E.M. Diets could prevent many diseases. Lipids 2003, 38, 317 - 321.

42. Horrobin, D.F. Fatty acid metabolism in health and disease: the role of $\Delta$-6-desaturase. Am. J. Clin. Nutr. 1993, 57, 732S - 736S.

43. Leakey, R.; Pate, K.; Lombard, C. Domestication potential of marula (Sclerocarya birrea subsp caffra) in South Africa and Namibia: 2. Phenotypic variation in nut and kernel traits. Agroforest. Syst. 2005, 64, $37-49$.

44. Kando, P.B.; Bisseye, C.; Nanema, R.K.; Traore, E.R.; Ye, H.; Diallo, B.O.; Compaore, T.R.; Simpore, J.; Zongo, J. Genetic diversity of Sclerocarya birrea subspecies birrea populations in Burkina Faso detected by RAPDs. Afr. J. Biotechnol. 2010, 11, 99 - 108.

45. Folch, J.; Lees, M.; Sloane-Stanley, G.H. A simple method for the isolation and purification of total lipids from animal tissue. J. Biol. Chem. 1957, 226, 497 - 509.

46. Park, Y.; Albright, K.J.; Cai, Z.Y.; Pariza, M.W. Comparison of methylation procedures for conjugated linoleic acid and artefact formation by commercial (trimethylsilyl) diazomethane. J. Agric. Food Chem. 2001, 49, 1158 - 1164.

47. Kramer, J.K.; Blackadar, C.B.; Zhou, J. Evaluation of two GC columns (60m Supelcowax 10 and 100m CP Sil 88) for analysis of milk fat with emphasis on CLA, 
18:1, 18:2 and 18:3 isomers, and short and long-chain fatty acids. Lipids 2002, 37, 823 $-835$.

48. Alfaia, C.M.M.; Castro, M.L.F.; Martins, S.I.V.; Portugal, A.P.V.; Alves, S.P.A.; Fontes, C.M.G.A.; Bessa, R.J.B.; Prates, J.A.M. Effect of slaughter season on fatty acid composition, conjugated linoleic acid isomers and nutritional value of intramuscular fat in Barrosã-PDO veal. Meat Sci. 2007, 75, 44 - 52.

49. Chilliard, Y.; Ferlay, A.; Rouel, J.; Lamberet, G. A review of nutritional and physiological factors affecting goat milk lipid synthesis and lypolysis. J. Dairy Sci. 2003, $86,1751-1770$.

50. Minitab. Minitab Statistical Software, Release 13.1 for Windows; Minitab Incorporation $^{\mathrm{TM}}$, USA, 2000.

51. Komane, B.; Vermaak, I.; Summers, B.; Viljoen, A. Safety and efficacy of Sclerocarya birrea (A. Rich.) Hochst (marula) oil: A clinical perspective. J. Ethnopharmacol. 2015, $176,327-335$.

52. Taseski, N. Supercritical fluid extraction of Sclerocarya birrea kernel oil. MSc Thesis, North-West University, RSA, 2015. Available online: https://repository.nwu.ac.za/handle/10394/15903 (Accessed 20 July 2019).

53. Nwabuebo, A.T. The effect of extraction methods on the oxidative stability of marula and moringa seed oil. MSc Thesis, University of KwaZulu-Natal, RSA, 2017. Available online:

https://researchspace.ukzn.ac.za/bitstream/handle/10413/15693/Nwabuebo_Anwuli_ \%20Tracey_\%202017.pdf?sequence=3\&isAllowed=y (Accessed 20 July 2019).

54. Gandure, J.; Ketlogetswe, C. Chemical extraction and property analyses of marula nut oil for biodiesel production. Adv. Chem. Eng. Sci. 2011, 1, 96-101. 
55. Cheikyoussef, N. Profiling studies of five Namibian indigenous seed oils obtained using three different extraction methods. PhD Thesis, University of Namibia, Namibia, 2018. Available

online: https://pdfs.semanticscholar.org/d902/90461a0d19ec3a314203c50a4b9058c00c97.pdf (Accessed 20 July 2019).

56. Hundessa, G. Extraction, optimization and characterization of Ethiopian marula (Sclerocarya birrea) and zigba (Podocarpus falcatus) oils. MSc Thesis, Addis Ababa University, Ethiopia, 2014. Available online: https://pdfs.semanticscholar.org/ecf5/275aafa272a0db0acbd9da4b997df69eeb88.pdf

57. Mariod, A.A.; Matthäus, B.; Idris, Y.M.A.; Abdelwahab, S.I. Fatty acids, tocopherols, phenolics and the antimicrobial effect of Sclerocarya birrea kernels with different harvesting dates. J. Am. Oil Chem. Soc. 2010, 87, 377 - 384.

58. Zharare, P.; Dhlamini, N. Characterization of marula (Sclerocarya caffra) kernel oil and assessment of its potential use in Zimbabwe. J. Food Technol. Afr. 2000, 5, $126-$ 128.

59. Mariod, A.A. Investigations on the oxidative stability of some unconventional Sudanese oils, traditionally used in human nutrition, $\mathrm{PhD}$ Thesis, Münster University, Germany, 2005.

60. Kadu, C.A.C.; Imbuga, M.; Jamnadass, R.; Dawson, I.K. Genetic management of indigenous fruit trees in southern Africa: A case study of Sclerocarya birrea based on nuclear and chloroplast variation. S. Afr. J. Bot. 2006, 72, $421-427$.

61. Helm, C.V.; Wilson, G.; Midgley, J.; Kruger, L.; Witkowski, E. T. Investigating the vulnerability of an African savanna tree (Sclerocarya birrea ssp. caffra) to fire and herbivory. Austral. Ecol. 2011, 36, $964-973$. 
62. Eaton, S.B.; Eaton, S.B. $3^{\text {rd}}$; Konner, M.J.; Shostak, M. An evolutionary perspective enhances understanding of human nutritional requirements. J. Nutr. 1996, 126, 1732 1740.

63. Simopoulos, A.P. Evolutionary aspects of diet, the omega-6/omega-3 ratio and genetic variation: nutritional implications for chronic diseases. Biomed. Pharmacother. 2006, $60,502-507$.

64. Lawrence, G.D. Dietary fats and health: dietary recommendations in the context of scientific evidence. Adv. Nutr. 2013, 4, $294-302$.

65. Vahmani, P.; Mapiye, C.; Prieto, N.; Rolland, D.C.; McAllister, T.A.; Aalhus, J.L.; Dugan, M.E.R. The scope for manipulating the polyunsaturated fatty acid content of beef: a review. J. Anim. Sci. Biotechnol. 2015, 6, 29.

66. Lopez-Huertas, E. Health effects of oleic acid and long chain omega-3 fatty acids (EPA and DHA) enriched milks. A review of intervention studies. Pharmacol. Res. 2010, 61, $200-2007$.

67. Mensink, R.P.; Zock, P.L.; Kester, A.D.; Katan, M.B. Effects of dietary fatty acids and carbohydrates on the ratio of serum total to HDL cholesterol and on serum lipids and apolipoproteins: a meta-analysis of 60 controlled trials. Am. J. Clin. Nutr. 2003, 77, $1146-1155$.

68. Kien, C.L. Dietary interventions for metabolic syndrome: role of modifying dietary fats. Curr. Diab. Rep. 2009, 9, $43-50$.

69. Samieri, C.; Feart, C.; Proust-Lima, C.; Peuchant, E.; Tzourio, C.; Stapf, C.; Berr, C.; Barberger-Gateau, P. Olive oil consumption, plasma oleic acid, and stroke incidence: the three-city study. Neurol. 2011, 77, $418-425$. 
70. Escrich, E.; Moral, R.; Grau, L.; Costa, I.; Solanas, M. Molecular mechanisms of the effects of olive oil and other dietary lipids on cancer. Mol. Nutr. Food Res. 2007, 51, $1279-1292$.

71. Menendez, J.A.; Papadimitropoulou, A.; Vellon, L.; Lupu, R. A genomic explanation connecting "Mediterranean diet", olive oil and cancer: oleic acid, the main monounsaturated fatty acid of olive oil, induces formation of inhibitory "PEA3 transcription factor-PEA3 DNA binding site" complexes at the Her-2/neu (erbB-2) oncogene promoter in breast, ovarian and stomach cancer cells. Eur. J. Canc. 2006, 42, $2425-2432$.

72. Kris-Etherton, P.M.; Pearson, T.A.; Wan, Y.; Hargrove, R.L.; Moriarty, K.; Fishell, V.; Etherton, T.D. High-monounsaturated fatty acid diets lower both plasma cholesterol and triacylglycerol concentrations. Am. J. Clin. Nutr. 1999, 70, 1009 - 1015.

73. Lopez-Miranda, J.; Perez-Jimenez, F.; Ros, E.; De Caterina, R.; Badimon, L.; Covas, M.I.; Escrich, E.; Ordovas, J.M.; Soriguer, F.; Abia, R.; de la Lastra, C.A.; Battino, M.; Corella, D.; Chamorro-Quirós, J.; Delgado-Lista, J.; Giugliano, D.; Esposito, K.; Estruch, R.; Fernandez-Real, J.M.; Gaforio, J.J.; La Vecchia, C.; Lairon, D.; LópezSegura, F.; Mata, P.; Menéndez, J.A.; Muriana, F.J.; Osada, J.; Panagiotakos, D.B.; Paniagua, J.A.; Pérez-Martinez, P.; Perona, J.; Peinado, M.A.; Pineda-Priego, M.; Poulsen, H.E.; Quiles, J.L.; Ramírez-Tortosa, M.C.; Ruano, J.; Serra-Majem, L.; Solá, R.; Solanas, M.; Solfrizzi, V.; de la Torre-Fornell, R.; Trichopoulou, A.; Uceda, M.; Villalba-Montoro, J.M.; Villar-Ortiz, J.R.; Visioli, F.; Yiannakouris, N. Olive oil and health: summary of the II international conference on olive oil and health consensus report, Jaen and Cordoba (Spain) 2008. Nutr. Metab. Cardiovasc. Dis. 2010, 20, 284 294. 
74. Klurfeld, D.M. Human Nutrition and Health Implications of Meat with More Muscle and Less Fat. In: Low-Fat Meats Design Strategies and Human Implications; Hafs, H.D., Zimbelman, R.G., Eds.; Academic Press, Inc.: New York, 1994, p. 35.

75. Turan, H.; Sönmez, G.; Kaya, Y. Fatty acid profile and proximate composition of the thornback ray (Raja clavata, L. 1758) from the Sinop coast in the Black Sea. J. Fish. Sci. 2007, 1, $97-103$.

76. Horcada, A.; Campo, M.D.M.; Polvillo, O.; Alcalde, M.J.; Cilla, I.; Sañudo, C. A comparative study of fatty acid profiles of fat in commercial Spanish suckling kids and lambs. Spanish J. Agric. Res. 2014, 12, 427 - 435.

77. Silva, T.M.; Oliveira, R.L.; Barbosa, L.P.; Neto, A.F.G.; Bagaldo, A.R.; Lanna, D.P.D.; da Silva, M.C.A.; de Jesus, I.B. Preliminary study on meat quality of goats fed levels of licury oil in the diet. Asian-Austral. J. Anim. Sci. 2011, 24, $1112-1119$.

78. Pan, D.A.; Lilloja, S.; Milner, M.R.; Kriketos, A.D.; Baur, L.A.; Bogardus, C.; Storlieni, L.H. Skeletal muscle membrane lipid composition is related to adiposity and insulin action. J. Clin. Invest. 1995, 96, $2802-2808$.

79. Murakami, K.; Sasaki, S.; Takahashi, Y.; Uenishi, K.; Watanabe, T.; Kohri, T.; Yamasaki, M.; Watanabe, R.; Baba, K.; Shibata, K.; Takahashi, T.; Hayabuchi, H.; Ohki, K.; Suzuki, J. Lower estimates of d-5 desaturase and elongase activity are related to adverse profiles for several metabolic risk factors in young Japanese women. Nutr. Res. 2008, 28, $816-824$.

80. Warensjö, E.; Rosell, M.; Hellenius, M.-L.; Vessby, B.; De Faire, U.; Risérus, U. Associations between estimated fatty acid desaturase activities in serum lipids and adipose tissue in humans: links to obesity and insulin resistance. Lipids Health Dis. 2009, 8,37 . 
81. Paillard, F.; Catheline, D.; Duff, F.L.; Bouriel, M.; Deugnier, Y.; Pouchard, M.; Daubert, J.C.; Legrand, P. Plasma palmitoleic acid, a product of stearoyl-CoA desaturase activity, is an independent marker of triglyceridemia and abdominal adiposity. Nutr. Metab. Cardiovasc. Dis. 2008, 18, 436 - 440.

82. Warensjö, E.; Riserus, U.; Vessby, B. Fatty acid composition of serum lipids predicts the development of the metabolic syndrome in men. Diabetol. 2005, 48, $1999-2005$.

83. Risérus, U.; Arnlöv, J.; Berglund, L. Long-term predictors of insulin resistance. Role of lifestyle and metabolic factors in middle-aged men. Diabet. Care 2007, 30, 29282933.

84. Warensjö, E.; Sundström, J.; Vessby, B.; Cederholm, T.; Risérus, U. Markers of dietary fat quality and fatty acid desaturation as predictors of total and cardiovascular mortality: a population based study. Am. J. Clin. Nutr. 2008, 88, $203-209$. 